\title{
Sexual Communication and Functioning among Adult Stroke Patients with Non-fluent Aphasia: A Cross-sectional Study
}

\author{
Blitzen Maximillan A. Espeleta, MD, ${ }^{1}$ Carl Froilan D. Leochico, MD ${ }^{1,2}$ and Jose Alvin P. Mojica, MD \\ ${ }^{1}$ Department of Rehabilitation Medicine, Philippine General Hospital, University of the Philippines Manila \\ ${ }^{2}$ Department of Physical Medicine and Rehabilitation, St. Luke's Medical Center, Global City and Quezon City, Philippines
}

\begin{abstract}
Background. Stroke remains a leading cause of death and disability in the Philippines, rendering its survivors unable to cope well with activities of daily living, including sexual functioning. Sexual dysfunction is an under-recognized complication post-stroke, and mobility and communication barriers among those with aphasia can further contribute to sexual dysfunction, potentially affecting their quality of life.
\end{abstract}

Objective. To determine the changes in sexual functioning among patients with aphasia and the communication methods they used to compensate for language and communication deficits.

Method. This was a descriptive cross-sectional study involving patients ( $\geq 30$ years old, with 1 episode of stroke, with non-fluent aphasia) and their respective sexual partners. Data were gathered using a clinician-administered questionnaire based on previous studies. Outcomes included changes in libido, coital frequency, time of resumption of sexual activity, erectile/ orgasmic ability, sexual satisfaction, and alternative methods of communication.

Results. Forty participants were included comprising of 20 patients with aphasia and their respective sexual partners. There was a decline in sexual activity among the couples, with reduced frequency of sexual intercourse. Both patients and partners reported difficulties in expressing the desire for sexual activities, hindering initiation. There was noted difficulty in ascertaining the sexual experience of patients with aphasia (i.e., whether pleasure or pain), hindering maintenance and enjoyment of the sexual act. In response to the difficulties mentioned above, sexual innuendoes as communication strategies were described by the couples.

Conclusion. The study provides baseline local data on changes in sexual functioning among stroke patients with nonfluent aphasia and their sexual partners. Sexual rehabilitation is recommended in the holistic management of patients with aphasia to train couples develop compensatory techniques to adjust to the changes in their sexual lives.

Keywords: stroke, aphasia, sexuality, sexual function, communication

\section{INTRODUCTION}

Stroke is the second leading cause of death in the Philippines and the leading cause of disability among Filipinos. ${ }^{1}$ Among stroke survivors, $33 \%$ present with aphasia and communication impairments leading them unable to express their needs and wants. Of particular interest would be the sexual needs of patients with aphasia. Several studies exclude patients with aphasia because of their inability or

Corresponding author: Jose Alvin P. Mojica, MD Department of Rehabilitation Medicine Philippine General Hospital University of the Philippines Manila

Taft Avenue, Ermita, Manila 1000, Philippines

Email: japmojica@post.upm.edu.ph difficulty expressing or comprehending their needs. Sex as an activity involves the intimacy of two persons, entailing proper communication of needs and wants. Among those with aphasia, communication is impaired, and sexual needs may not be conveyed at all. The ability to create and sustain 
intimate relationships remains a crucial part of human life. Sexual problems are considered among the main reasons for marital conflicts even post-stroke. ${ }^{2}$

Sexuality is a subject that is not often addressed in the rehabilitation of stroke survivors in various healthcare settings. Many clinicians would often overlook sexual health. Similarly, patients and their partners may also be apprehensive in consulting about their concerns related to sexuality. Furthermore, prior related studies involving patients with stroke often excluded those with aphasia because they could not participate in interviews or complete self-administered questionnaires. However, it was found that couples eventually develop different expressions and strategies to resume sexual communication and activities after stroke. ${ }^{3}$ Sexual rehabilitation may help couples formulate practical strategies to overcome difficulties related to sexual dysfunction and inactivity.

Aphasia can significantly impact sexuality among patients and their partners compared to stroke survivors without language and communication deficits. ${ }^{4}$ Unfortunately, it is not well recognized and addressed in the clinic. The topic's sensitive nature may entail cultural change towards the normalization of sexuality in health-related discussions poststroke. Practical strategies, such as increasing awareness, providing correct information, addressing misconceptions, and suggesting tips and positions to promote healthy and safe sex, may be helpful to couples and can be incorporated into standard care policies. Prior studies suggested that such policy changes require attention as soon as possible. ${ }^{2,4}$

This study aimed to determine the changes in sexual functioning among stroke patients with aphasia, the effect of aphasia on the relationship of the stroke patient with his/her sexual partner, and the adaptive or compensatory strategies that the couples developed to communicate sexual matters. Results of the study can provide initial local, albeit limited, data on this population and serve as a benchmark for future larger-scale studies and sexual rehabilitation recommendations.

\section{METHODS}

\section{Study Design and Participants}

This descriptive cross-sectional study included patients $\geq 30$ years of age with first-time stroke, confirmed by cranial computed tomography scan, magnetic resonance imaging, or both, of at least three months in duration. Patients understood spoken Filipino, English, or both languages with functional gross hearing and vision. The patients were evaluated to have either Broca's aphasia, transcortical motor aphasia, or anomic aphasia based on the Bedside Western Aphasia Battery Test. The Boston Classification of Aphasia characterizes patients with Broca's, transcortical motor, or anomic aphasia to have poor fluency but with good understanding and relatively spared reading comprehension, thus allowing the present study's patients to provide consent reliably. ${ }^{5}$ The patients gave their voluntary informed consent either by writing or thumbprint. The patients were accompanied by their sexual partners, who were also recruited in the study.

Patients with two or more strokes, other forms of aphasia, and the absence of a regular sexual partner were excluded from the study. Those with severe hearing and visual impairments or psychological disorders, such as depression, that required medication were also excluded. To maintain homogeneity in the study population, any couple was excluded if both of them had a previous stroke, in a same-sex relationship, or both.

\section{Study Procedure}

Ethical approval was obtained from the institutional review board. Participants underwent routine physiatric examination and were recruited from the hospital's outpatient department and pool of patients participating in speech therapy. They underwent aphasia evaluation using the Bedside Western Aphasia Battery Revised Test (WAB-R Bedside) conducted by a licensed speech-language pathologist. The WAB-R Bedside is a diagnostic tool used to evaluate language among adults with suspected neurological disorders (e.g., stroke, head injury, dementia). It was constructed as a shorter and quicker version of the original instrument. It could be administered using only a Record Form and readily available items at the bedside (e.g., photograph, coin, sheet of paper, pen). ${ }^{6}$

Each stroke survivor and his/her sexual partner were interviewed separately. A closed-door interview was conducted with each participant in a private, quiet room (without a video surveillance camera) in the study institution. Data were obtained individually using a set of clinicianadministered questionnaires based on previous studies., ${ }^{2,4,7}$, The questionnaire inquired about each participant's sexual functioning pre- and post-stroke. The study utilized the "Supported Conversation for Adults with Aphasia" (SCA) method that used pictograms from the SCA "Participics" database to aid in the interview of aphasic patients. The pictograms were used to formulate a communication board to facilitate adaptive conversation. ${ }^{4}$ The patients in the study utilized the communication board in answering the close-ended questions. The comprehension of the included patients was deemed sufficient and reliable for data gathering, given the aid of the communication board that showed pictograms corresponding to different possible answers for each question. The patients pointed at the specific pictogram corresponding to their answers. During data analysis, their responses were verified by comparing them with the reactions of their respective sexual partners. Answers without wide discrepancies between each couple were considered comparable. In contrast, couples with incomparable or different answers were re-interviewed separately to clarify the questions and ensure response accuracy without disclosing any answer from either side.

Data privacy and confidentiality were ensured throughout the study. Each participant was assigned a unique 
code and did not have an identifier on the data collection form. The participant identifiers were only available on the informed consent form. Only the study investigators have access to the data collection and informed consent forms. During the interview, it was carefully ensured that no answer from a participant was mentioned or disclosed to his/ her respective partner.

\section{Data Analysis}

The sample size was computed based on the department census of stroke patients seen annually. Using an online opensource calculator (OpenEpi ${ }^{\mathrm{TM}}$, version 3), the population size was entered as 21 with the following preset parameters: $95 \%$ as a confidence interval, $50 \pm 5 \%$ as hypothesized $\%$ frequency of outcome factor in the population, and 1 as design effect. The computed sample size was 20 participants. The level of significance was set at $\mathrm{p} \leq 0.05$.

The independent study variables included the following: (1) continuous quantitative data (i.e., age, duration of stroke) were presented using mean, and standard deviation; and (2) binary data (i.e., sex, laterality of brain lesion) and (3) categorical data (i.e., civil status) were presented using frequency and percentage.

The dependent study variables were categorized as follows: (1) changes in libido (normal/ increased, decreased, or no libido); (2) sexual frequency (normal/ increased, decreased, or no change); (3) sexual arousal, either erection for males or vaginal lubrication/ orgasm for females (normal/ increased, decreased, no change, or no erection/ orgasm); and (4) satisfaction with sexual life (satisfied or not satisfied). A Chi-square test was used in comparing the sexual functioning outcomes post-stroke between patients and their sexual partners.

The participants' responses regarding the effect of aphasia on sexuality and the couple's relationship and the communication methods they developed in response to changes in their sexual functioning were presented according to common themes in frequencies and percentages.

\section{RESULTS}

Forty participants or twenty couples were included in the study. The mean age of the participants, whether patients or sexual partners, ranged from 40 to 45 years (Table 1). The majority of the patients were males and married. The mean duration of the stroke was $4 \pm 2.24$ years. The majority (57\%) had Broca's aphasia, and all patients presented with one-sided weakness and spasticity.

The study participants (patients and their respective sexual partners) recalled their sexual functioning or experiences regarding libido, frequency, erection or vaginal lubrication, and sexual satisfaction before and after the stroke. Each parameter was rated as "normal" when there was a perception of having the usual or unchanged level of sexual functioning compared to the recent years preceding the
Table 1. Demographic data of participants

\begin{tabular}{|c|c|c|}
\hline Characteristic & $\begin{array}{c}\text { Aphasic patients } \\
(n=20) \\
n(\%) \text { or } X \pm S D\end{array}$ & $\begin{array}{c}\text { Sexual partners } \\
(n=20), \\
n(\%) \text { or } X \pm S D\end{array}$ \\
\hline \multicolumn{3}{|l|}{ Demographic factors } \\
\hline Age, years & $45 \pm 7.69$ & $40 \pm 6.91$ \\
\hline \multicolumn{3}{|l|}{ Sex } \\
\hline Males & $16(75)$ & $4(25)$ \\
\hline Females & $4(25)$ & $16(75)$ \\
\hline \multicolumn{3}{|l|}{ Civil Status } \\
\hline Single & $2(11)$ & $2(11)$ \\
\hline Married & $18(89)$ & $18(89)$ \\
\hline Separated & $0(0)$ & $0(0)$ \\
\hline Widow/er & $0(0)$ & $0(0)$ \\
\hline \multicolumn{3}{|l|}{ Clinical factors } \\
\hline Duration of stroke, years & $4 \pm 2.24$ & Not applicable \\
\hline \multicolumn{3}{|l|}{ Type of stroke } \\
\hline Ischemic & $17(83)$ & \\
\hline Hemorrhagic & $3(17)$ & \\
\hline \multicolumn{3}{|l|}{ Type of aphasia } \\
\hline Broca's & $14(57)$ & \\
\hline Transcortical motor & $6(43)$ & \\
\hline Anomic & $0(0)$ & \\
\hline \multicolumn{3}{|l|}{ Presence of other impairments } \\
\hline Hemiplegia/ hemiparesis & $20(100)$ & \\
\hline Spasticity & $20(100)$ & \\
\hline
\end{tabular}

stroke. As such, all the participants reported relatively normal or even increased sexual functioning across all measured parameters before the stroke (Table 2). The majority noted decreased sexual functioning after the stroke, particularly libido, sexual frequency, and vaginal lubrication. However, there was no change in the level of erection in most of the male participants.

The responses of patients were elicited by pointing to pictograms. Libido was generally decreased among patients (75\%) and partners (70\%). On the other hand, three patients claimed that they had an increased libido after the stroke. One of these claims was consistent with the interview of the patient's wife, as she explained that they had been spending more time with each other after the stroke. Nonetheless, sexual frequency was decreased for all couples. Among the male patients, the majority (50\%) had no change in their erections, while others reported either a decrease or increase in the frequency of their erections. Among the female participants, whether patients or sexual partners, a majority reported decreased vaginal lubrication. Among the patients, whether males or females, there was a significant decrease in sexual satisfaction $(p<0.05)$. On the other hand, among the sexual partners, the decrease in sexual satisfaction was not statistically significant $(\mathrm{p}>0.05)$.

Table 3 shows that all patients had resumed some form of sexual activity after the stroke. For this study, "sexual activity" included intercourse, touching genitals, bodycaressing, and intimate hugging, kissing, and talks about sex or sexual feelings. Only one couple reported that they had 
Table 2. Sexual functioning before and after stroke

\begin{tabular}{|c|c|c|c|c|c|c|}
\hline \multirow{2}{*}{$\begin{array}{l}\text { Sexual functioning } \\
\text { outcomes }\end{array}$} & \multicolumn{2}{|c|}{ Before stroke, $\mathrm{n}(\%)$} & \multicolumn{2}{|c|}{ After stroke, n (\%) } & \multirow{2}{*}{ Chi-square test } & \multirow{2}{*}{ p-value } \\
\hline & Patients $(n=20)$ & Partners $(n=20)$ & Patients $(n=20)$ & Partners $(n=20)$ & & \\
\hline $\begin{array}{l}\text { Libido } \\
\text { Normal/Increased } \\
\text { Decreased } \\
\text { No change } \\
\text { No libido }\end{array}$ & $\begin{array}{l}20(100) \\
0(0) \\
0(0) \\
0(0)\end{array}$ & $\begin{array}{l}20(100) \\
0(0) \\
0(0) \\
0(0)\end{array}$ & $\begin{aligned} 3 & (15) \\
15 & (75) \\
2 & (10) \\
0 & (0)\end{aligned}$ & $\begin{array}{c}0(0) \\
14(70) \\
6(30) \\
0(0)\end{array}$ & Not applicable & Not applicable \\
\hline $\begin{array}{l}\text { Sexual frequency } \\
\text { Normal/Increased } \\
\text { Decreased } \\
\text { No change }\end{array}$ & $\begin{array}{c}20(100) \\
0(0) \\
0(0) \\
\end{array}$ & $\begin{array}{c}20(100) \\
0(0) \\
0(0)\end{array}$ & $\begin{array}{c}0(0) \\
20(100) \\
0(0) \\
\end{array}$ & $\begin{array}{c}0(0) \\
20(100) \\
0(0) \\
\end{array}$ & Not applicable & Not applicable \\
\hline $\begin{array}{l}\text { Erection } \\
\text { Normal/Increased } \\
\text { Decreased } \\
\text { No change } \\
\end{array}$ & $\begin{array}{c}16(100) \\
0(0) \\
0(0) \\
\end{array}$ & $\begin{array}{l}4(100) \\
0(0) \\
0(0)\end{array}$ & $\begin{array}{r}3(15) \\
7(35) \\
10(50) \\
\end{array}$ & $\begin{array}{l}0(0) \\
0(0) \\
4(100)\end{array}$ & Not applicable & Not applicable \\
\hline $\begin{array}{l}\text { Vaginal lubrication } \\
\text { Normal/Increased } \\
\text { Decreased } \\
\text { No change } \\
\end{array}$ & $\begin{array}{l}4(100) \\
0(0) \\
0(0) \\
\end{array}$ & $\begin{array}{c}16(100) \\
0(0) \\
0(0) \\
\end{array}$ & $\begin{array}{l}0(0) \\
3(67) \\
1(33) \\
\end{array}$ & $\begin{array}{c}0(0) \\
4(66.7) \\
12(33.3) \\
\end{array}$ & Not applicable & Not applicable \\
\hline $\begin{array}{l}\text { Sexual satisfaction } \\
\text { Satisfied } \\
\text { Not satisfied }\end{array}$ & $\begin{array}{c}19(95) \\
1(5)\end{array}$ & $\begin{array}{r}18(90) \\
2(10) \\
\end{array}$ & $\begin{array}{r}4(20) \\
16(80)\end{array}$ & $\begin{array}{r}16(80) \\
4(20) \\
\end{array}$ & $\begin{array}{c}\text { For patients: } 23.0179 \\
\text { For partners: } 0.1961\end{array}$ & $\begin{array}{l}\text { For patients: } 0.0002 \\
\text { For partners: } 0.65791\end{array}$ \\
\hline
\end{tabular}

Table 3. Psychosocial factors affecting sexual function between aphasic individuals and their sexual partners

\begin{tabular}{|c|c|c|c|c|c|c|}
\hline \multirow{2}{*}{ Psychosocial factors } & \multicolumn{2}{|c|}{ Before stroke, n (\%) } & \multicolumn{2}{|c|}{ After stroke, n (\%) } & \multirow{2}{*}{ Chi-square test } & \multirow{2}{*}{ p-value } \\
\hline & Patients $(n=20)$ & Partners $(n=20)$ & Patients $(n=20)$ & Partners $(n=20)$ & & \\
\hline $\begin{array}{l}\text { Resumption of sexual } \\
\text { activity after stroke } \\
\quad<1 \text { month } \\
\geq 1 \text { month } \\
<6 \text { months } \\
\geq 6 \text { months }\end{array}$ & Not applicable & Not applicable & $\begin{aligned} 2 & (10) \\
1 & (5) \\
3 & (15) \\
14 & (70)\end{aligned}$ & $\begin{aligned} & 2(10) \\
1 & (5) \\
3 & (15) \\
14 & (70)\end{aligned}$ & Not applicable & Not applicable \\
\hline $\begin{array}{l}\text { Fears from sexual activity } \\
\text { Recurrence of stroke } \\
\text { Heart attack } \\
\text { Pain } \\
\end{array}$ & Not applicable & Not applicable & $\begin{array}{c}20(100) \\
20(100) \\
5(25) \\
\end{array}$ & $\begin{array}{l}20(100) \\
20(100) \\
16(80) \\
\end{array}$ & Not applicable & Not applicable \\
\hline $\begin{array}{l}\text { Perceived importance } \\
\text { of sexual activity } \\
\text { Important } \\
\text { Not important } \\
\end{array}$ & $\begin{array}{r}17(85) \\
3(15) \\
\end{array}$ & $\begin{array}{r}16(80) \\
4(20) \\
\end{array}$ & $\begin{array}{r}15(75) \\
5(25) \\
\end{array}$ & $\begin{array}{r}12(60) \\
8(40) \\
\end{array}$ & $\begin{array}{l}\text { For patients: } 0.625 \\
\text { For partners: } 1.9048\end{array}$ & $\begin{array}{l}\text { For patients: } 0.4291 \\
\text { For partners: } 0.1675\end{array}$ \\
\hline $\begin{array}{l}\text { Professional consults regar- } \\
\text { ding sexuality after stroke } \\
\text { Present } \\
\text { Absent }\end{array}$ & Not applicable & Not applicable & $\begin{array}{r}2(10) \\
18(90) \\
\end{array}$ & $\begin{array}{r}2(10) \\
18(90) \\
\end{array}$ & Not applicable & Not applicable \\
\hline $\begin{array}{l}\text { Desire for professional } \\
\text { consult on sexuality } \\
\text { Yes } \\
\text { No }\end{array}$ & Not applicable & Not applicable & $\begin{array}{r}17(85) \\
3(15)\end{array}$ & $\begin{array}{r}14(70) \\
6(30)\end{array}$ & Not applicable & Not applicable \\
\hline
\end{tabular}

not resumed intercourse since the stroke. All patients and their partners expressed their concerns and fears about the resumption of sexual activities. Their apprehensions came from fears of a recurrence of the stroke or the occurrence of a heart attack. Some patients, primarily females, expressed concerns related to musculoskeletal, genitalia pain, or both. Meanwhile, most sexual partners expressed fear of pain for their partners during any sexual act, especially intercourse. They were sometimes unsure of the patients' responses, whether they were feeling pleasure or pain. Sexual activity was generally regarded as necessary among couples before and after the stroke. Even though there was a decline in their self-perceived importance of sexual activity after the stroke, the changes were not statistically significant for patients and partners alike $(\mathrm{p}>0.05)$.

Table 4 shows the couples' responses regarding the effect of self-perceived problems or apprehensions on their sexual activities. Among the problems identified, all couples 
Table 4. Perceived problems or apprehensions related to sexual activity

\begin{tabular}{lcc|}
\multicolumn{1}{|c}{ Perceived problems } & $\begin{array}{c}\text { Aphasic patients } \\
(\mathbf{n}=20), \mathbf{n}(\%)\end{array}$ & $\begin{array}{c}\text { Sexual partners } \\
(\mathbf{n}=20), \mathbf{n}(\%)\end{array}$ \\
\hline $\begin{array}{l}\text { Fear of recurrent stroke } \\
\text { Fear of heart attack }\end{array}$ & $20(100)$ & $20(100)$ \\
$\begin{array}{l}\text { Difficulty understanding each } \\
\text { other }\end{array}$ & $20(100)$ & $20(100)$ \\
$\begin{array}{l}\text { Difficulty in talking about sex } \\
\text { with partner }\end{array}$ & $20(100)$ & $13(65)$ \\
$\begin{array}{l}\text { Aphasia or communication } \\
\text { deficits }\end{array}$ & $20(100)$ & $20(100)$ \\
$\begin{array}{l}\text { Misunderstanding of pain or } \\
\text { pleasure }\end{array}$ & $4(20)$ & $16(80)$ \\
Role reversal & $0(0)$ & $15(75)$ \\
\hline
\end{tabular}

Table 5. Communication strategies of expressing sexuality

\begin{tabular}{lrc} 
Communication strategies & $\begin{array}{c}\text { Aphasic patients } \\
(\mathbf{n = 2 0}) \mathbf{n}(\%)\end{array}$ & $\begin{array}{c}\text { Sexual partners } \\
(\mathbf{n = 2 0}) \mathbf{n}(\%)\end{array}$ \\
$\begin{array}{l}\text { Initiating sexual activity } \\
\text { Verbalizing }\end{array}$ & $4(20)$ & $20(100)$ \\
Touching & $17(85)$ & $18(90)$ \\
Groping & $15(75)$ & $13(65)$ \\
Tongue-clicking & $3(15)$ & $0(0)$ \\
Smiling & $2(10)$ & $2(10)$ \\
\hline Maintaining sexual activity & & \\
Verbalizing & $3(15)$ & $20(100)$ \\
Moaning & $15(75)$ & $18(90)$ \\
Groping & $13(65)$ & $20(100)$ \\
Touching & $7(35)$ & $20(100)$ \\
\hline Resolving sexual activity & & \\
Orgasm & $16(80)$ & $4(20)$ \\
Verbalizing & $4(20)$ & $16(80)$ \\
Tapping & $6(30)$ & $15(75)$ \\
Spanking & $4(20)$ & $0(0)$ \\
\hline
\end{tabular}

expressed fears of a recurrent stroke and heart attack. They also described their difficulties in understanding each other, which led to problems during sexual activity. Aside from the sexual act itself, both parties expressed difficulty talking to their partners regarding their desires for sex. Some sexual partners claimed that the aphasic partner could no longer express their feelings or engage in sexually meaningful conversations. Most couples said that the aphasia negatively impacted their sex life. An improvement in individuals' communication skills would improve their sex life and potentially their quality of life as a couple.

Table 5 shows the communication strategies used by the couples in terms of initiating, maintaining, and resolving sexual activity. Since the partners had no physical or communication deficits, they had no problems verbalizing their desires for sexual activity. Some aphasic individuals could communicate their desires for sexual activity without any problem by using sexual innuendoes or cues they were used to before the stroke. Some relied on other physical senses, such as touch, to express their desire for sexual activity. Despite the difficulties in expression, several couples learned to develop their method of understanding each other sexually. These couples were able to facilitate sexual activity either by touching or groping. Two aphasic individuals used facial expressions to initiate sexual activity. This was confirmed during an interview with their partners.

Meanwhile, some used tongue clicking to express sexual desires. In resolving the sexual act, all the male participants were determined with the occurrence of orgasm. Among the female aphasics, the resolution of the sexual act was facilitated by tapping or spanking their partners.

Lastly, there were no adverse events that occurred throughout and beyond the study conduct. All patients and their partners had continued to regularly follow-up with their physiatrists, and nothing alarming was reported as a physical or psychological consequence of study participation.

\section{DISCUSSION}

This study confirmed the decline in sexual activity among couples affected by stroke and aphasia. The patients and their partners reported difficulties in expressing sexual desires, hindering initiation of the sexual act. There was also noted difficulty in ascertaining the health, safety, and sexual experience of stroke patients, hindering maintenance and enjoyment of the sexual act. In response to the difficulties mentioned above, sexual innuendoes as communication strategies were developed by the couples.

Changes in sexuality following stroke have attracted the interest of clinical researchers, but prior studies seldom included aphasic individuals, who comprise one-third of the stroke population. ${ }^{4}$ Studies frequently excluded aphasic individuals because of the difficulty in obtaining data from this population. Local data on the changes in sexual functioning associated with stroke survivors, particularly the decline in coital frequency among others (i.e., a decline in libido, sexual arousal, and satisfaction), were significantly associated with psychosocial factors, such as attitude towards sexual intercourse, ability to discuss sexual matters, and willingness to participate in sex. ${ }^{2}$

A crucial part of human life is the ability to create and sustain intimate relationships. Several studies point out negative changes after stroke, leading to decreased sexual functioning and potentially quality life. Sexuality remains one of the unmet needs after stroke, and dysfunction often leads to frustration breaks in relationships, divorce, and separation. ${ }^{9}$

\section{Change in sexual behavior}

There was a reduced frequency of sexual intercourse among all couples. One couple reported that they had not resumed intercourse since the stroke. The majority attributed their change in sexual behavior to the decrease in libido and orgasm. Despite the decline in the frequency of intercourse, most couples reported an increase in other sexual activities, such as genital touching, caressing the body, kissing, and hugging. 
On the other hand, some patients reported increased libido after the stroke. It was noted that spending more quality time with a sexual partner at home could improve sexual functioning. During the coronavirus disease 2019 pandemic, wherein home quarantine is widely implemented, it may seem that couples spending time at home may have a longer opportunity to be intimate with each other and even develop verbal and non-verbal strategies to potentially address their previous sexual inactivity.

\section{Impact of aphasia on sexuality}

The aphasic individuals confirmed their difficulty in verbally expressing their desire for sexual activities. The problem in communication limited their ability to initiate sexual activity. However, some couples had developed their techniques for initiating, maintaining, and resolving their sexual activities without verbal communication. The sexual innuendoes differed from couple to couple and were individually established and formed by the couples based on their experiences and body language.

\section{Role reversal}

A prominent theme identified during the interviews was a role reversal, mainly expressed by the sexual partners. It could be inferred that the aphasic individuals had a decrease in participation during the sexual act because of their physical impairments. The change in role between patient and partner appears to be a contributory factor since the patient changed from being a participant to a psychologically maladjusted spectator due to performance anxiety and fear of relapse. They could not "perform" like before, leading to reduced self-esteem and transition to becoming a frustrated sexual spectator. Role expectations and role changes control both the patient's and partner's adjustment to the new life situation. The spouse tends to become ambivalent towards sex. ${ }^{10}$

\section{Access to information regarding sexuality after stroke}

The majority of the couples reported that their healthcare providers did not ask them about their experiences or concerns regarding sexuality since the stroke. These couples also said that they were not comfortable bringing up sexuality during consultations, but they would have appreciated it if someone had initiated the topic. Only 2 of the couples reported that they were asked about their sexuality. When given a chance, couples were interested in speaking with their physicians regarding sexual activity, mainly healthrelated risks. Other concerns identified were alternative sexual positions, side effects of medications, and medical treatments for sexual dysfunction.

\section{Aphasia and sexuality}

Aphasia was described to affect sexuality differently than for post-stroke with intact language ability. As expressed by the participants, it is believed that an improvement in communication skills would improve sexuality. ${ }^{4}$ Aphasia affected their ability to initiate sexual activity. Another factor that led to the decline in sexual activity was the inability of the aphasic individuals to discuss sexuality openly with their partners, consistent with the literature. ${ }^{2,9}$

The strength of the present study was the inclusion of individuals with aphasia, who were typically excluded in many prior studies. ${ }^{4}$ Although it was challenging, data collection was completed to verify data through separate interviews with the sexual partners. A limitation of the study was related to the small number of participants. The number of participants in this study was based on the limited number of patients with aphasia seen and assessed in one institution only and within a relatively short recruitment period. The effect of aphasia on same-sex relationships was not explored in the study, but it could be an interesting area for future research.

Furthermore, since the study design was crosssectional and there were no available data documenting the participants' baseline sexual functioning before the stroke, the data were based on self-reports, potentially prone to recall bias. It could be helpful if clinicians and researchers would have baseline data on sexual functioning early after stroke and at specific intervals thereafter to determine the changes that might occur over time and institute possible sexual rehabilitation interventions, as deemed necessary on a case-by-case basis. It would have also been helpful to the present study if all the participants, especially the patient counterparts, had undergone baseline mental status, memory, and/or other cognitive tests to objectively ascertain their ability to comprehend and recall accurately and provide more objectively reliable data.

The major challenge for the study was the communication barrier. Despite the intact comprehension of the patients, the impaired fluency hindered verbal communication. Data had to be presented so that questions were not open-ended but rather close-ended, using a communication board with pictograms corresponding to potential answers. Because of such limitations, the data collected were more quantitative rather than qualitative, explorative, or in greater depth. Due to the language impairments of the patients, eliciting answers to open-ended questions would have been difficult and prone to misinterpretations. Nonetheless, the study contributed to that gap in knowledge on sexual functioning, specifically among stroke patients with aphasia.

\section{CONCLUSION}

This study provides baseline local data on the changes in sexual functioning that patients with non-fluent aphasia and their sexual partner's experience. There is a noted decrease in sexual frequency and activity among these couples. However, the couples have developed compensatory techniques to facilitate their sexual desires. These techniques could be taught and improved during sexual rehabilitation. Sexual 
needs and dysfunctions of couples affected by stroke and aphasia should not be overlooked to provide holistic care to patients and their partners.

\section{Statement of Authorship}

All authors participated in the data collection and analysis and approved the final version submitted.

\section{Author Disclosure}

All authors declared no conflicts of interest.

\section{Funding Support:}

No funding support.

\section{REFERENCES}

1. The Stroke Society of the Philippines. SSP handbook of stroke: guidelines for prevention, treatment, and rehabilitation. Quezon City, Philippines: Golden Pages Publishing Company; 2014.

2. Leochico CFD, Mojica JAP, Ignacio SD, Dy-Mancao B. Sexual functioning after stroke among Rehabilitation Medicine outpatients and their sexual partners: a cross-sectional study. Acta Med Philipp. 2020;54(2):161-6.
3. Thompson S, Walker L. Sexual dysfunction after stroke: underestimating the importance of psychological and physical issues. Webmed Central Phys Med 2011;2(12).

4. Lemieux L, Cohen-Schneider R, Holzapfel S. Aphasia and sexuality. Sex Disabil 2001;19:253-66.

5. Goodglass H, Kaplan E, Barresi B. Boston diagnostic aphasia examination, 3rd ed. Philadelphia: Lippincott, Williams \& Wilkins; 2001.

6. Kertesz A, Raven J. Western aphasia battery revised examiner's manual. Dallas: Pearson; 2007.

7. Korpelainen JT, Nieminen P, Myllylä V V. Sexual functioning among stroke patients and their spouses. Stroke. 1999;30(4):715-9.

8. Monga T, Lawson J, James I. Sexual dysfunction in stroke patients. Arch Phys Med Rehabil 1986;67(1):19-22.

9. Shah M. Sexuality after stroke. In: Stein J, Harvey LR, Macko FR, Winstein JC, Zorowitz DR, editors. Stroke, Recovery and Rehabilitation. New York: Demos Medical Publishing; 2009.

10. Sjögren K, Fugl-Meyer A. Adjustment to life after stroke with special reference to sexual intercourse and leisure. J Psychosom Res. 1982;26(4):409-17. 